\title{
Production of levulinic acid from glucose in sulfolane/water mixtures
}

\author{
Marja Mikola*, Juha Ahola, Juha Tanskanen \\ Chemical Process Engineering Research Unit, Faculty of Technology, P.O. Box 4300, FI-90014 \\ University of Oulu, Finland \\ * Corresponding author. Tel. +358 29448 2565; E-mail address: marja.mikola@ oulu.fi
}

\begin{abstract}
Levulinic acid derived from biomass is a versatile platform molecule, which can be used in manufacturing different compounds to replace fossil-based chemicals. In this study, the effect of sulfolane as solvent in sulphuric acid catalysed levulinic acid production from glucose was investigated. The broad sulfolane concentration range was systematically studied and a kinetic model was developed to describe the levulinic acid production. A significant increase in glucose conversion rate was observed when the proportion of sulfolane in the solvent mixture was increased. The maximum selectivity of the levulinic acid production was found to be slightly over $50 \%$ and independent of the solvent composition. Thus, with sulfolane solvent, the same yields can be obtained in a significantly shorter time or at a lower temperature as when water is used as solvent. Sulfolane was also found to keep the generated by-products in soluble form. This will decrease fouling of the process equipment, which has been a major issue in designing of levulinic acid production processes.
\end{abstract}

\section{Keywords}

biorefining, levulinic acid, reaction kinetics, solvent effect, glucose conversion 


\section{Introduction}

The increasing demand of chemicals and energy together with diminishing petroleum sources has led to major efforts in the development of renewable replacements for fossil raw materials. Lignocellulosic biomass is a renewable feedstock for manufacturing organic chemicals that is throughout the world abundant. Thus, production of platform molecules from lignocellulosic biomass has a key role in developing alternatives for fossil-based chemicals. These platform molecules can be produced from biomass and then upgraded further into a wide range of different chemicals and fuel components.

Levulinic acid has been recognized as one of the most promising platform molecules that can be produced from biomass (Bozell and Petersen, 2010). From an industrial perspective, the most suitable route for manufacturing levulinic acid starts from polymeric carbohydrates. Cellulose is the most abundant polymeric carbohydrate in lignocellulosic biomass and thus a very attractive raw material for levulinic acid production. To produce levulinic acid, cellulose first needs to be hydrolysed into glucose, which is then converted to 5-hydroxymethylfurfural (HMF), and further to levulinic acid and formic acid. A well-known approach for this is treatment under acidic conditions at elevated temperatures. (Kang et al., 2018; Mukherjee et al., 2015; Morone et al, 2015; Pileidis and Titirici, 2016).

The acid-catalysed production of levulinic acid from glucose in water with different acid catalysts has been studied extensively. The kinetics of levulinic acid production have been studied using sulphuric acid (Chang et al., 2006; Girisuta et al., 2006), hydrochloric acid (Weingarten et al., 2012) and formic acid (Kupiainen et al., 2011) as catalyst. Generally, the findings are quite similar regardless of the acid used. Parallel reactions causing the formation of by-products, humins, have been found to occur in both reaction steps. The formation of humins results in significant yield losses in levulinic acid production. It is also generally recognised that to achieve high glucose conversions within a reasonable time, high temperatures or high acid catalyst concentrations need to be applied. 
Although increasing the amount of acid catalyst speeds up the conversion, it may cause corrosion problems and especially with sulphuric acid difficulties in the catalyst recycle. The increase in reaction temperature leads to an increase in operation costs and in addition there are findings that very high temperatures decrease the levulinic acid selectivity (Girisuta et al., 2006).

The use of organic solvents in biomass conversion reactions offers a way to enhance the reaction rate without increasing the amounts of acid catalyst amounts or temperatures used. Besides the reaction rates, the use of organic solvents has been found to have a positive effect on the selectivities in some applications. A wide range of organic solvents, including dimethyl sulfoxide (Chen et al., 2017), tetrahydrofuran (He et al., 2017), gamma-valerolactone (Alonso et al., 2013; Wettstein et al., 2012) and methyl isobutyl ketone (Brasholz et al., 2011) has been studied with the aim of enhancing the production of platform chemicals. Most of the research has been focused on the effects of solvent on HMF formation and much less on levulinic acid production. (Shuain and Luterbacher, 2016; Mukherjee et al., 2015) Although the general effects of different solvents on biomass conversion reactions have been studied to some extent, a systematic investigation of the effect of solvent concentrations on the reaction kinetics is still lacking.

Sulfolane is a commonly known industrial solvent. It is relatively stable up to $220^{\circ} \mathrm{C}$ and has good solvent properties. Sulfolane has been principally used as an extraction solvent in oil refining to extract aromatic hydrocarbons, i.e. benzene, toluene and xylene, from aliphatic hydrocarbons. It is also commercially used in gas treatment to remove acidic compounds such as hydrogen sulphide from natural gas. (Clark, 2000) Sulfolane has also been found to be an applicable solvent in some biorefining applications such as pyrolysis of cellulose (Bao et al., 2008; Kawamoto et al., 2003), delignification of biomass (Wang et al., 2016), cellulose conversion into chemicals (Wang et al., 2017) and production of 5-hydroxymethylfurfural from fructose (Caes and Raines, 2011). Considering also the challenges involved in the separation of valuable components produced in biorefining applications, sulfolane has been found to have positive effects. Specifically, replacing 
water with sulfolane leads to decrease in energy consumption of levulinic acid recovery by distillation. (Tuppurainen et al., 2018) The effect of sulfolane on glucose decomposition into levulinic acid has not been reported earlier. Thus, detailed information about the effects of sulfolane to levulinic acid productions kinetics is still lacking.

In this work, the sulphuric acid catalysed production of levulinic acid in sulfolane/water mixtures was studied. The effects of the sulfolane amount, temperature and reaction time on the kinetics of levulinic acid production as well as yields and selectivities were investigated. To produce a comprehensive kinetic model describing levulinic acid production from glucose, in addition to glucose, the intermediate product HMF was also used as starting material.

\section{Experimental}

\subsection{Materials}

The chemicals used were obtained as follows, glucose from VWR Chemicals, sulphuric acid from Merck, levulinic acid and sulfolane from Alfa Aesar and HMF from Sigma-Aldrich. All chemicals were analytical grade and used without further purification. All solutions were prepared in ultrapure water (resistivity $18.2 \mathrm{M} \Omega \cdot \mathrm{cm}$ ).

\subsection{Experimental procedures}

Solvents-catalyst mixtures containing desired amounts of sulfolane, water and sulphuric acid were prepared by weighing the appropriate amount of each chemical for the mixture. Sulfolane concentration in the mixtures varied from 0 to $90 \mathrm{wt} \%$. The sulphuric acid concentration used was 1 $\mathrm{wt} \%$. Experiments were carried out with an initial glucose concentration of $110 \mathrm{mM}$ or initial $\mathrm{HMF}$ concentration of $80 \mathrm{mM}$. For most of the experiments, homogenous solutions containing the starting material, catalyst and solvents were prepared by weighing the desired amount of starting material in a volumetric flask and filling it with the pre-prepared solvent-catalyst mixture. The complete 
dissolution of the starting material was verified before the experiments. Since $110 \mathrm{mM}$ of glucose is not completely soluble in $90 \mathrm{wt} \%$ sulfolane at room temperature, in the case of these experiments, glucose was dosed directly into the reactor in which the solvent-catalyst mixture was added.

Experiments were carried out in zirconium batch reactors with a sample amount of $20 \mathrm{ml}$. The reaction mixture was pipetted into the reactors, which were closed with zirconium caps equipped with a PTFE-coated thermocouple for temperature measurements. The reactors were heated using a preheating oven operating at a temperature of about $400{ }^{\circ} \mathrm{C}$. When the temperature of the reactors reached $10{ }^{\circ} \mathrm{C}$ lower values than the desired reaction temperature, they were moved to a fluidised sand bath operating at the reaction temperature where the temperature remained constant. After the reaction time, the reaction was quenched by moving the reactors from the sand bath into ice water, which resulted in the rapid cooling of the reactors. The warm up times varied between 3-4 minutes and cooling from the reaction temperature to room temperature took about 1 minute. Samples were taken from the cooled reaction mixtures and diluted with water. After the dilution, the samples were filtered through a $0.45 \mu \mathrm{m}$ syringe filter before HPLC analysis. Samples were diluted to avoid precipitation of the by-products during the analysis, since the by-products formed are soluble in sulfolane but not in water.

In order to study the effect of sulfolane concentration on the production of levulinic acid from glucose, experiments were conducted with seven different sulfolane concentrations: $0,10,30,50,70$, 80 and $90 \mathrm{wt} \%$. With all of the sulfolane concentrations experiments were conducted at three different temperatures with three reaction times at each temperature. The temperatures varied between 140 and $180^{\circ} \mathrm{C}$ and reaction times varied between 30 and 120 minutes. Reaction times and temperatures were chosen for each sulfolane concentration so that adequate conversions were reached under all the studied conditions. Thus, for low sulfolane concentrations higher temperatures were used and vice versa. All the reported yields are molar-based yields. 


\subsection{Analytical method}

The amounts of glucose, levulinic acid and HMF were measured with HPLC system (Agilent Technologies) equipped with Rezex ROA Organic acid $\mathrm{H}^{+}$column (Phenomenex). $5 \mathrm{mM}$ sulphuric acid was used as mobile phase with the flow rate of $0.8 \mathrm{ml} / \mathrm{min}$ and the column was operated at the temperature of $60^{\circ} \mathrm{C}$. $\mathrm{HMF}$ was detected with diode array detector set at wavelength of $280 \mathrm{~nm}$, the other measured compounds were detected with refractive index detector. The quantitation of the compounds was based on multiple point external calibration. The validity and stability of the calibration was confirmed by measuring control samples with each sample sequence, which contained on average ten samples.

\subsection{Kinetic modelling}

Kinetic modelling was carried out in the Matlab environment. The systems of ordinary differential equations (ODEs), representing batch reactors, were solved numerically by ode $15 \mathrm{~s}$, a solver for stiff ODE systems. Despite the fact that the duration of the heating up and cooling down periods was minor compared to the reaction times used, the non-isothermality was taken into account with linear interpolation. Reaction rate parameters were estimated by non-linear regression analysis. The estimation was done by using the trust region reflective algorithm available within the Matlab lsqcurvefit function. 


\section{Results and discussion}

\subsection{Effect of sulfolane concentration}

The effect of sulfolane concentration on the achieved glucose conversion and levulinic acid yield is illustrated in Fig. 1. Data from all of the experiments using glucose as starting material including glucose conversions, yields of intermediate product HMF and yields and selectivities of final product levulinic acid are reported in the supplementary material. It can be seen from Fig. 1 that increasing the sulfolane concentration leads to an increase in glucose conversion and levulinic acid yield obtained at the same temperature and with the same reaction time. Even though the increase in sulfolane concentration systematically increases the conversion and yield, the differences between water and lowest studied sulfolane concentrations were minor. However, when the sulfolane concentration was increased sufficiently, the effect on reaction rate was drastic, especially when 90 wt $\%$ sulfolane was used as solvent. Generally, it can be noted that a full conversion of glucose can be achieved with all of the sulfolane concentrations used, but when higher sulfolane concentrations are used, shorter times are adequate to reach it. Similar reaction rate increasing effect has been reported also earlier when studying acid catalytic reaction of sugar in $\gamma$-valerolactone (GVL), which is a polar aprotic solvent similar to sulfolane. Significant increase in turnover frequency of xylose was reported especially when using strong acid such as sulphuric acid as catalyst. (Mellmer et al., 2014) GVL/water mixture has been studied also in the production of levulinic acid from cellulose with solid acid catalyst. The trend reported for levulinic acid yield was similar than obtained in this study. (Alonso et al., 2013) 

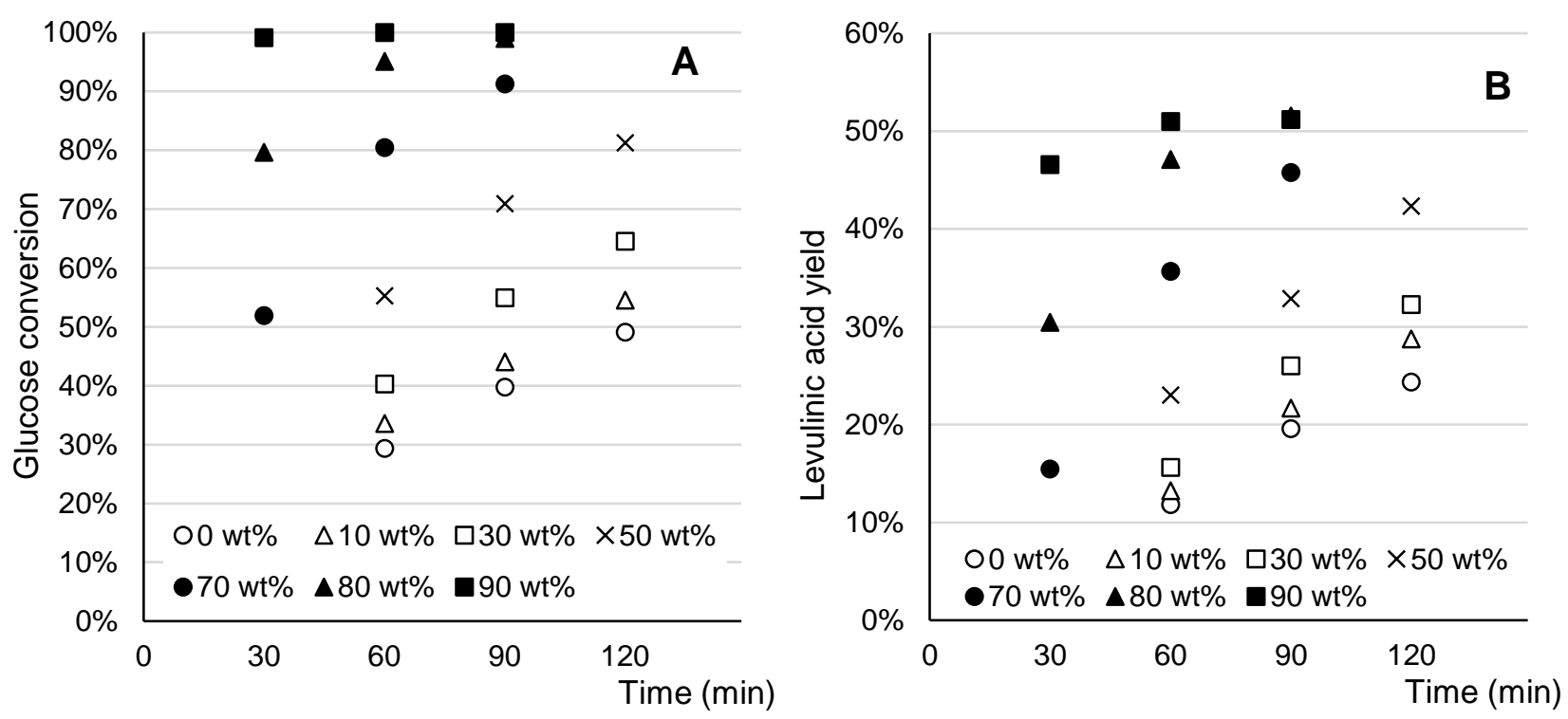

Fig. 1. Effect of sulfolane concentration on glucose conversion (A) and levulinic acid yield (mol/mol) (B) at $160{ }^{\circ} \mathrm{C}$.

Whereas the sulfolane concentration was found to have a clear effect on the rate of glucose conversion, it did not have an effect on the selectivity towards levulinic acid production. The highest levulinic acid yields obtained were slightly over $50 \%$ and could be obtained at any of the studied sulfolane concentrations as long as the reaction was conducted under such conditions that the conversion of glucose was complete. Typical reported levulinic acid yields obtained from glucose on laboratory scale vary between 30-60 \% (Kang et al., 2018; Morone et al., 2015; Mukherjee et al., 2015). Thus, the yields obtained in this study are well in line with previous findings.

Slight differences in reaction behaviour with different sulfolane concentrations are revealed when comparing levulinic acid yields to the glucose conversions with which they were obtained. In Fig. 2a the levulinic acid yields obtained are represented as a function of glucose conversion. It can be seen that while the reaction is proceeding, i.e. glucose conversion is significantly under $100 \%$, at higher sulfolane concentrations levulinic acid yields are lower. This can be explained by differences in the formation of the intermediate product HMF. When higher concentrations of sulfolane were used, higher HMF yields were observed. The highest HMF yields were detected at the highest sulfolane concentrations and with the shortest studied reaction times. Increasing the reaction time led 
to the conversion of the formed HMF to levulinic acid with high selectivity. As shown in Fig. 2b, when the sum of HMF and levulinic acid yields is compared to the glucose conversion, no differences between solvent compositions are seen. It has been reported also in the literature that the use of dimethyl sulfoxide (DMSO), another polar aprotic solvent, results higher HMF concentration compared to the use of water when producing levulinic acid from cellulosic food waste with solid acid catalyst. (Chen et al., 2017)
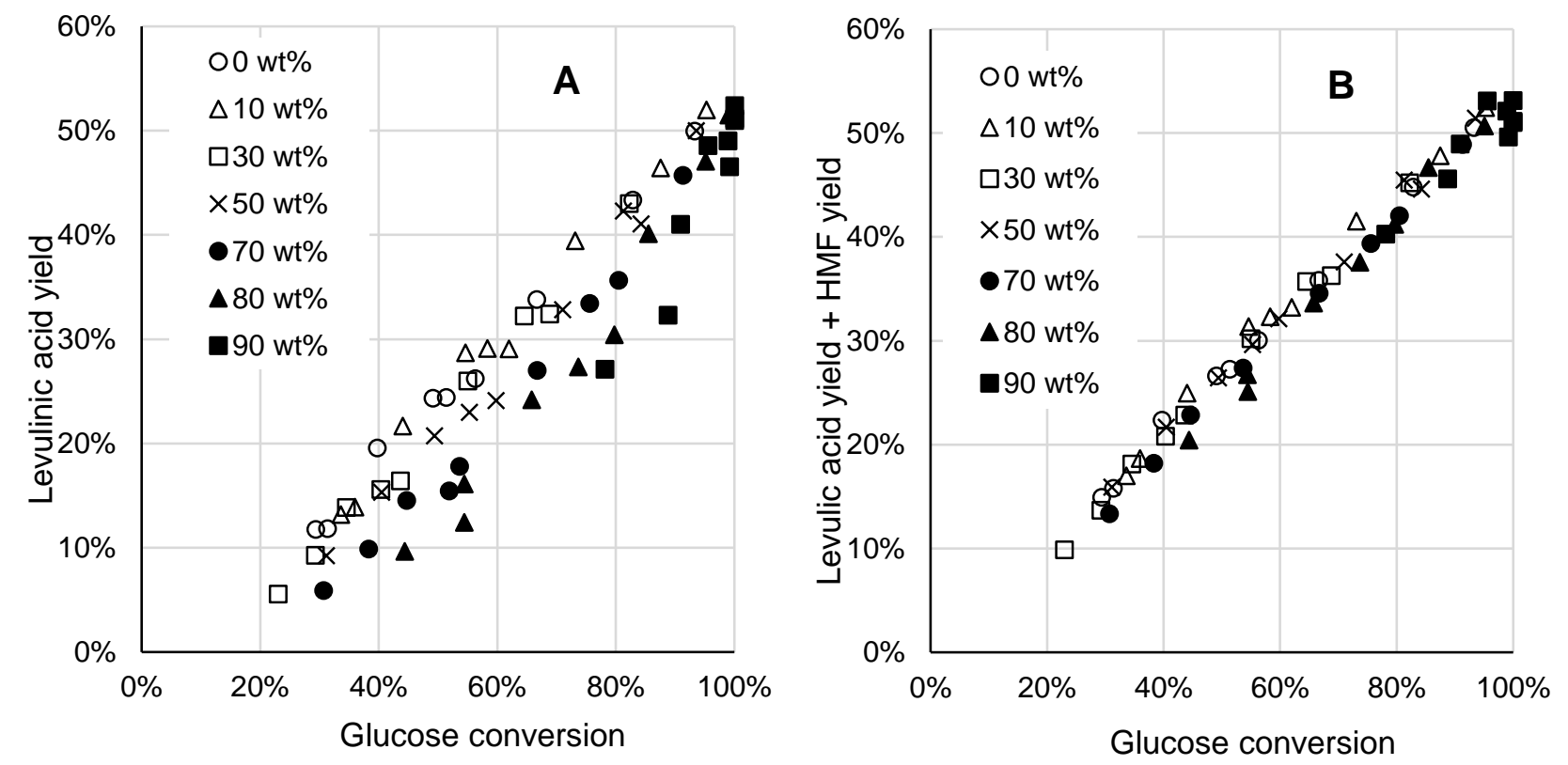

Fig. 2. Levulinic acid yield (A) and sum of levulinic acid and HMF yields (B) as a function of glucose conversion at different sulfolane concentrations.

To reveal more detailed information about the effect of the sulfolane concentration on levulinic acid production and to enable accurate kinetic modelling, experiments with HMF as starting material were carried out. Data from the experiments using HMF as starting material are reported in the supplementary material. The main finding was that HMF converts to levulinic acid with very high selectivity and increasing the sulfolane concentration increases this selectivity even further. The highest levulinic acid yields obtained without sulfolane and with $90 \mathrm{wt} \%$ sulfolane were $84 \%$ and 93 $\%$, respectively. The corresponding yields at other studied sulfolane concentrations formed a 
systematic trend between these values. The effect of the solvent concentration on the rate of HMF conversion is discussed in detail in the next chapter concerning kinetic modelling results.

\subsection{Kinetics of levulinic acid production in sulfolane/water mixtures}

The overall reaction scheme for glucose conversion to levulinic acid is shown in Fig. 3. Firstly, the glucose reacts in two irreversible parallel reactions: reaction 1 being a glucose dehydration reaction to form HMF and reaction 3 being the glucose reaction to form undesirable by-products, humins. The formed HMF then also undergoes two irreversible parallel reactions: namely, a rehydration reaction to form levulinic acid together with formic acid (reaction 2) and a reaction to form humin by-products (reaction 4).

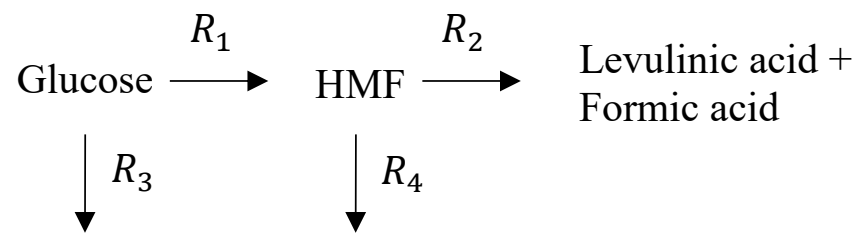

Humins Humins

Fig. 3. Reaction scheme for glucose conversion to levulinic acid.

When first order kinetics are assumed for every reaction step the rate equations for the reactions shown in Fig. 3 are as shown in equations 1-4. The temperature dependence of the reaction rate parameters is taken into account by the reparameterised Arrhenius equations as shown in equation 5 .

$$
\begin{aligned}
& R_{1}=k_{1} C_{\mathrm{H}_{2} \mathrm{SO}_{4}} C_{G l u} \\
& R_{2}=k_{2} C_{\mathrm{H}_{2} \mathrm{SO}_{4}} C_{\mathrm{HMF}} \\
& R_{3}=k_{3} C_{\mathrm{H}_{2} \mathrm{SO}_{4}} C_{G l u} \\
& R_{4}=k_{4} C_{\mathrm{H}_{2} \mathrm{SO}_{4}} C_{\mathrm{HMF}}
\end{aligned}
$$




$$
k_{i}=k_{r e f, i} e^{-\frac{E_{a, i}}{R}\left(\frac{1}{T}-\frac{1}{T_{r e f}}\right)} \quad i=1,2,3,4
$$

where $\mathrm{k}_{\mathrm{ref}}$ is the reaction rate constant in the reference temperature, $\mathrm{T}_{\mathrm{ref}}$ is the reference temperature, $\mathrm{E}_{\mathrm{a}}$ is the activation energy and $\mathrm{R}$ is the gas constant.

The catalytic effect of sulphuric acid is included with the molar concentration of sulphuric acid. This is very similar to the $\mathrm{H}^{+}$concentration because the first dissociation constant of sulphuric acid is large and the second dissociation constant is very small, and both of them are virtually temperatureindependent at the studied temperature range.

When the reactions are carried out in a batch reactor, the mass balance for each component can be presented as shown in equations 6-8:

$$
\begin{aligned}
& \frac{d C_{G l u}}{d t}=-R_{1}-R_{3} \\
& \frac{d C_{H M F}}{d t}=R_{1}-R_{2}-R_{4} \\
& \frac{d C_{L A}}{d t}=R_{2}
\end{aligned}
$$

The mass balance was solved and the parameters were estimated independently at each sulfolane concentration for all four reactions using the data from experiments with both glucose and HMF as starting materials. Although the main focus of this study is on investigating glucose conversion to levulinic acid, the data from the experiments using HMF as starting material was necessary to include in the kinetic modelling to identify the parameters of the HMF reactions correctly. The temperature dependence of the reaction rates was found to be independent of the sulfolane concentration. Thus, activation energies were estimated to apply to all of the sulfolane concentrations. On the other hand, reaction rate constants at the reference temperature were estimated for each sulfolane concentration. 
The parity plot including measured and modelled glucose, HMF and levulinic acid concentrations is shown in Fig. 4. The values shown in the parity plot are scaled with the maximum concentration of each component. The proposed model with estimated parameters fits well with experimental findings. The $\mathrm{R}^{2}$ value is $99.95 \%$. In addition, there are no anomalies in the parity plot. In the supplementary material the model prediction of the concentrations as well as measured concentrations for different compounds at different reaction conditions are shown. The good agreement between model and experimental findings can be seen also from those figures.

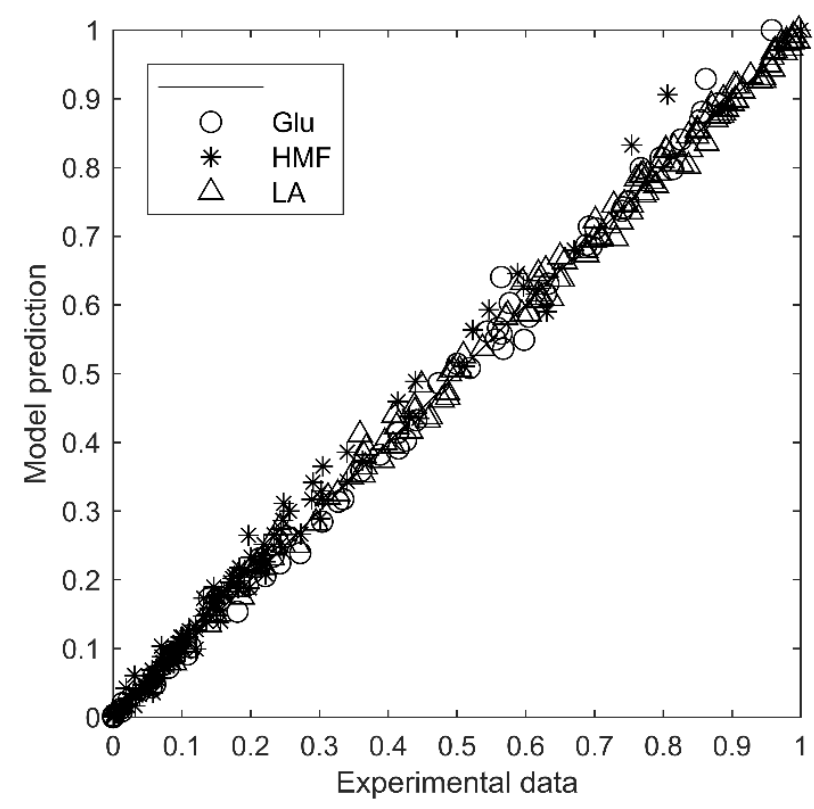

Fig. 4. Parity plot including all measured and modelled concentrations.

The effect of sulfolane on reaction rate parameters is shown in Fig. 5. Sulfolane has an increasing effect on the reaction rate throughout the concentration range when the reactions of glucose are taken into consideration. The rate-increasing effect applies to both reactions, glucose dehydration to HMF and formation of humin by-products from glucose. At lower sulfolane concentrations, the effect is minor but high sulfolane concentrations cause a significant increase in reaction rates. The reaction rate constants for glucose dehydration to $\operatorname{HMF}\left(\mathrm{k}_{1}\right)$ are slightly higher than the reaction rate constants for humin formation from glucose $\left(\mathrm{k}_{3}\right)$ throughout the sulfolane concentration range. The 
magnitude of the rate-increasing effect of the sulfolane is slightly lower for the glucose to HMF reaction than for the humin formation reaction. Thus, the selectivity of HMF formation from glucose is slightly decreased due to the use of the sulfolane solvent.

The effect of sulfolane on the reactions of HMF is much weaker than on the reactions of glucose. In addition, the trends are more complicated than those with the glucose reactions. Whereas the reaction rates of the glucose reactions were found to systematically increase with increasing sulfolane concentrations, for HMF reactions the reaction rates were found to first decrease and then increase with increasing sulfolane concentrations. The trend of the effect was similar with both of the reactions of HMF. It was observed that the magnitude of the changes in the reaction rates is such that the ratio of the rate constants $\mathrm{k}_{2}$ and $\mathrm{k}_{4}$ is increased by the use of sulfolane, leading to the higher selectivity of levulinic acid formation from HMF. The rate-increasing effect of the sulfolane was found to be stronger for the HMF formation reaction than for the HMF conversion reactions, leading to an increase in the concentration of the intermediate product HMF. This behaviour was also observed in the experimental results. 

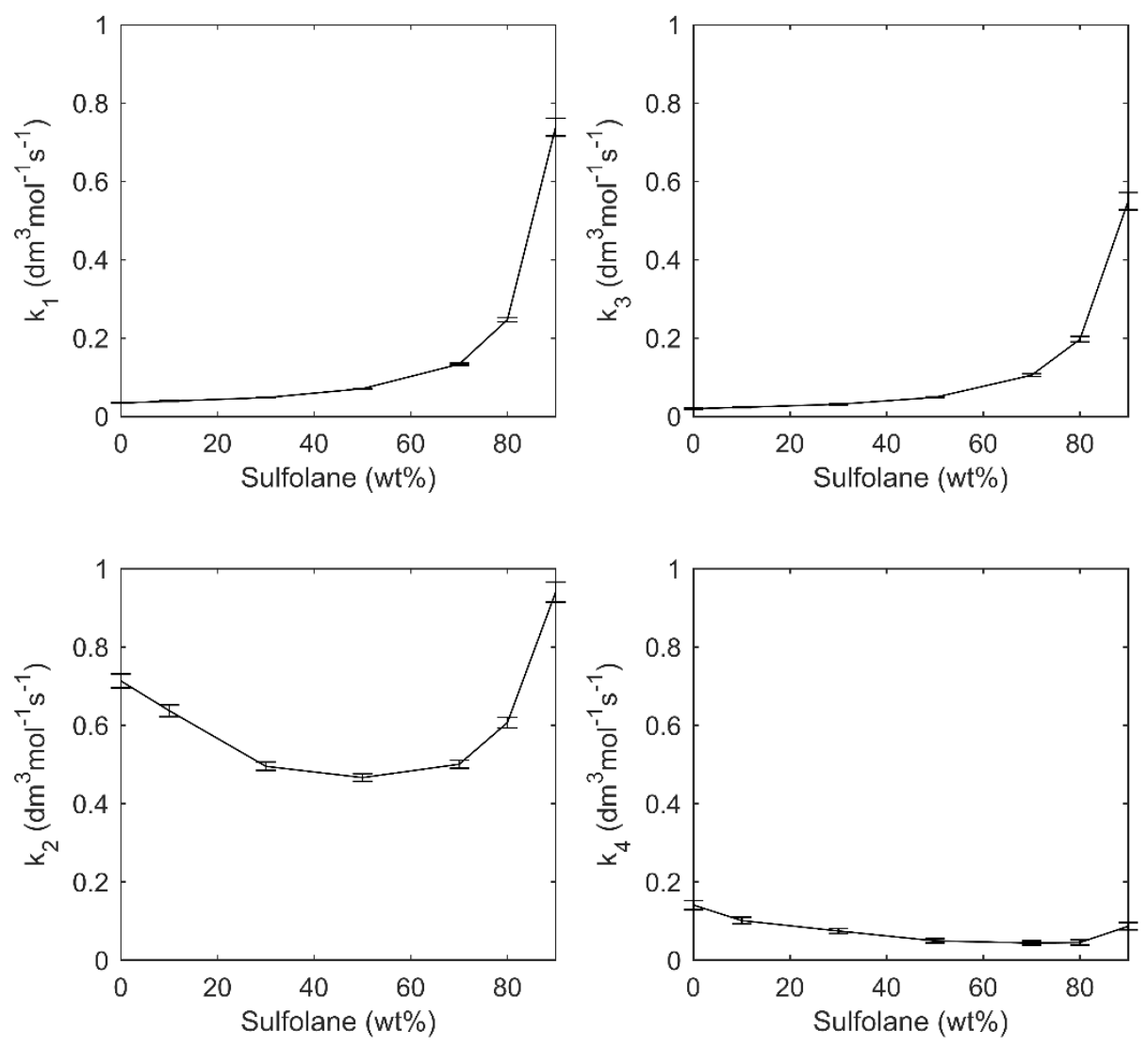

Fig. 5. Reaction rate constants at reference temperature $160^{\circ} \mathrm{C}$ as a function of sulfolane content (wt\%) with $95 \%$ confidence region based on t-distribution.

In the experimental study, the selectivity of levulinic acid production from glucose was found to be unaffected by the sulfolane concentrations. The results of the kinetic modelling support this finding. In the first reaction step, the selectivity of the glucose conversion to HMF is slightly decreased by the use of sulfolane, but in the second reaction step, the selectivity of HMF conversion to levulinic acid is increased when sulfolane is used. Together, these changes result in the fact that the selectivity of levulinic acid formation from glucose remains constant regardless of the use of sulfolane. In addition, the magnitude of the highest experimentally obtained levulinic acid yield can be explained by the kinetic findings. Since $\mathrm{k}_{1}$ was found to be slightly higher than $\mathrm{k}_{2}$, somewhat over half of the glucose forms $\mathrm{HMF}$ and because $\mathrm{k}_{3}$ is much higher than $\mathrm{k}_{4}$, the majority of the formed 
HMF is converted to levulinic acid. This leads to about $50 \%(\mathrm{~mol} / \mathrm{mol})$ levulinic acid selectivity, which was also observed.

The changes in reaction rates observed when using the sulfolane solvent are due to changes in the activity of the reacting molecules. The reaction rate is a function of the activities of the starting materials and reaction rate constants. Thus, the reaction rate constants estimated in this study also include the activity coefficients of the reacting compounds. Mellmer et al. (2014) have suggested that, in water acid protons are more stabilised due to solvation by water molecules than in organic solvents. This leads to lower reactivity of the acid catalyst in water than in organic solvents. This behaviour partially explains the observations made in this study. Since the effect of the sulfolane solvent is different in the conversion of glucose compared to the conversion of HMF, both of which are acidcatalysed reactions, sulfolane also has to have an effect on the reactivity of reaction compounds other than the acid catalyst. It is also generally observed in previous studies that, as well as affecting the behaviour of the catalyst, organic solvents do affect the interactions of the reactants, transition stages and products (Shuain and Luterbacher, 2016).

Table 1. Estimated activation energies with $95 \%$ confidence region based on t-distribution.

\begin{tabular}{ll}
\hline Parameter & Value \\
\hline $\mathrm{E}_{\mathrm{a}, 1}$ & $134 \pm 1.6 \mathrm{~kJ} / \mathrm{mol}$ \\
$\mathrm{E}_{\mathrm{a}, 2}$ & $94.4 \pm 1.4 \mathrm{~kJ} / \mathrm{mol}$ \\
$\mathrm{E}_{\mathrm{a}, 3}$ & $131 \pm 2.6 \mathrm{~kJ} / \mathrm{mol}$ \\
$\mathrm{E}_{\mathrm{a}, 4}$ & $94.7 \pm 6.4 \mathrm{~kJ} / \mathrm{mol}$ \\
\hline
\end{tabular}

Estimated activation energies are shown in Table 1. When the confidence intervals are taken into account, the activation energies for the parallel reaction of glucose conversion are equal. The same applies to the competing conversion reactions of HMF. Hence, based on these estimations, temperature does not have an effect on the selectivity of the levulinic acid production from glucose. 
This is supported by the experimental findings in this study where levulinic acid was obtained with similar selectivity regardless of the temperature used. Earlier findings considering sulphuric acid catalysed glucose conversion have reported that the glucose conversion to by-products has higher activation energy than glucose conversion to $\mathrm{HMF}$, which leads to a loss in selectivity at high temperatures (Girisuta et al., 2006). The differences in the findings may be due to the fact that, in their study, some of the experiments were conducted at a higher temperature $\left(200{ }^{\circ} \mathrm{C}\right)$ than in this study, which may have changed the dominating reaction mechanism of the by-product formation. 


\section{Conclusions}

The effect of the use of sulfolane solvent on the sulphuric acid catalysed production of levulinic acid from glucose was studied and a kinetic model was created to describe the levulinic acid production. The solvent was found to cause a significant increase in the reaction rate of glucose conversion. Based on the kinetic findings, sulfolane causes a slight decrease in the selectivity of the formation of the intermediate product, HMF, from glucose but increases the selectivity of HMF conversion to levulinic acid. Thus, the selectivity of levulinic acid formation from glucose was not affected by the use of sulfolane and a levulinic acid yield of slightly over $50 \%$ was obtained regardless of the sulfolane concentration.

Since sulfolane accelerates the conversion of glucose without influencing the maximum yield of levulinic acid, the same production of levulinic acid can be obtained at a lower temperature or with a shorter residence time as when using water as solvent. Sulfolane was also found to keep the generated by-products in soluble form, which decreases fouling of the process equipment. Taking into account the increase of reaction rate and decrease of fouling of the process equipment observed in this study, together with the increase of the energy efficiency of the separation section reported earlier, replacing water with sulfolane could offer notable advantages in designing of levulinic acid manufacturing processes.

\section{Supplementary data}

Supplementary data associated with this article can be found in the online version. 


\section{Acknowledgements}

The financial support from the ERDF projects "Biomass value chains" (EURA 2014/2191/09 0201

01/2015/KPLIITTO) and "Value adding of forest biomass - Raw materials from side products of biorefining" (EURA 2014/5099/09 0201 01/2017/PPL) is gratefully acknowledged.

\section{Declaration of interest}

None. 


\section{References}

Alonso, D.M., Gallo, J.M.R., Mellmer, M.A., Wettstein, S.G., Dumesic, J.A., 2013. Direct conversion of cellulose to levulinic acid and gamma-valerolactone using solid acid catalysts. Catal. Sci. Technol. 3, 927-931. https://doi.org/10.1039/c2cy20689g

Bao, G.-R., Saka, S., Wang, H., 2008. Cellulose decomposition behavior in hot-compressed aprotic solvents. Sci. China Ser. B: Chem. 51, 479-486. https://doi.org/10.1007/s11426-008-0052-1

Branholz, M., Von Känel, K., Hornung, C.H., Saubern, S., Tsanaktsidis, J., 2011. Highly efficient dehydration of carbohydrates to 5-(chloromethyl)furfural (CMF), 5-(hydroxymethyl)furfural (HMF) and levulinic acid by biphasic continuous flow processing. Green Chem. 13, 1114-1117. https://doi.org/10.1039/c1gc15107j.

Boszell, J.J., Petersen, G.R., 2010. Technology development for the production of biobased production from biorefinery carbohydrates - the US Department of Energy's “Top 10"revisited. Green Chem. 12, 539-554. https://doi.org/10.1039/b922014c.

Caes, B.R., Raines, R.T., 2011. Conversion of Fructose into 5-(Hydroxymethyl)furfural in Sulfolane. ChemSusChem 4, 353-356. https://doi.org/10.1002/cssc.201000397.

Chang, C., Ma, X., Cen, P., 2006. Kinetics of Levulinic Acid Formation from Glucose Decomposition at High Temperature. Chinese J. Chem. Eng. 14, 708-712. https://doi.org/10.1016/S10049541(06)60139-0. 
Chen, S.S., Yu, I.K.M., Tsang, D.C.W., Yip, A.C.K., Khan, E., Wang, L., Ok, Y.S., Poon, C.S., 2017. Valorization of cellulosic food waste into levulinic acid catalysed by heterogeneous Brønsted Acids: Temperature and solvent effects. Chem. Eng. J. 327, 328-335. https://doi.org/10.1016/j.cej.2017.06.108.

Clark, E., 2000. Sulfolane and Sulfones. In Kirk-Othmer Encyclopedia of Chemical Technology, (Ed.). John Wiley \& Sons. https://doi.org/10.1002/0471238961.1921120603120118.a01.

Girisuta, B., Janssen, L.P.B.M., Heeres, H.J., 2006. Green chemicals: A Kinetic Study on the Conversion of Glucose to Levulinic Acid. Chem. Eng. Res. Des. 84, 339-349. https://doi.org/10.1205/cherd05038.

He, J., Liu, M., Huang, K., Walker, T.W., Maravelias, C.T., Dumesic, J.A., Huber, G.W., 2017. Production of levoglucosenone and 5-hydroxymethylfurfural from cellulose in polar aprotic solventwater mixtures. Green Chem. 19, 3642-3653. https://doi.org/10.1039/c7gc01688c.

Kang, S., Fu, J., Zhang, G., 2018. From lignocellulosic biomass to levulinic acid: A review on acidcatalyzed hydrolysis. Renew. Sustain. Energy Rev. 94, 340-362. https://doi.org/10.1016/j.rser.2018.06.016.

Kawamoto, H., Hatanaka, W., Saka, S., 2003. Thermochemical conversion of cellulose in polar solvent (sulfolane) into levoglucosan and other low molecular-weight substances. J. Anal. Appl. Pyrolysis 70, 303-313. https://doi.org/10.1016/S0165-2370(02)00160-2. 
Kupiainen, L., Ahola, J., Tanskanen, J., 2011. Kinetics of glucose decomposition in formic acid. Chem. Eng. Res. Des. 89, 2706-2713. https://doi.org/10.1016/j.cherd.2011.06.005.

Mellmer, M.A., Sener, C., Callo, J.M.R., Luterbacher, J.S., Alonso, D.M., Dumesic, J.A., 2014 Solvent Effects in acid-calalyzen Biomass Conversion Reactions. Angew. Chem. Int. Ed. 53, 11872 -11875. https://doi.org/10.1002/anie.201408359.

Morone, A., Apte, M., Pandey, R.A., 2015. Levulinic acid production from renewable waste resources: Bottlenecks, potential remedies, advancements and applications. Renew. Sustain. Energy Rev. 51, 548-565. https://doi.org/10.1016/j.rser.2015.06.032.

Mukherjee, A., Dumont, M.-J., Raghavan, V., 2015. Review: Sustainable production of hydroxymethylfurfural and levulinic acid: Challenges and opportunities. Biomass Bioenergy 72, 143183. https://doi.org/10.1016/j.biombioe.2014.11.007.

Pileidis, F.D., Titirici, M.-M., 2016. Levulinic Acid Biorefineries: New Challenges for Efficient Utilization of Biomass. ChemSusChem 9, 562-582. https://doi.org/10.1002/cssc.201501405.

Shuain, L., Luterbacher, J., 2016. Organic Solvent Effects in Biomass Conversion Reactions. ChemSusChem 9, 133-155. https://doi.org/10.1002/cssc.201501148.

Tuppurainen, V., Ahola, J., Tanskanen J., 2018. Effect of organic solvents in separation section of levulinic acid production: Syntheis of distillation sequences. Chem. Eng. Trans. 69, 235-240. https://doi.org/10.3303/CET1869040. 
Wang, K., Xie, X., Jiang, J., Wang, J., 2016. Sulfolane pretreatment of shrub willow to improve enzymatic saccharification. Cellulose 23, 1153-1163. https://doi.org/10.1007/s10570-016-0875-4.

Wang, K., Ye, J., Zhou, M., Liu, P., Liang, X., Xu, J., Jiang, J., 2017. Selective conversion of cellulose to levulinic acid and furfural in sulfolane/water solvent, Cellulose 24, 1383-1394. https://doi.org/10.1007/s10570-016-1184-7.

Weingarten, R., Cho, J., Xing, R., Conner, W.C., Huber, G.W., 2012. Kinetics and Reaction Engineering of Levulinic Acid Production from Aqueous Glucose Solutions. Chemsuschem 5, 12801290. https://doi.org/10.1002/cssc.201100717.

Wettstein, S.G., Alonso, D.M., Chong, Y., Dumesic, J.A., 2012. Production of levulinic acid and gamma-valerolactone (GVL) from cellulose using GVL as a solvent in biphasic systems. Energy Environ. Sci. 5, 8199-8203. https://doi.org/10.1039/c2ee22111j. 